\title{
Heat wave characteristics in the eastern Mediterranean and Middle East using extreme value theory
}

\author{
M. Tanarhte ${ }^{1, *}$, P. Hadjinicolaou ${ }^{2}$, J. Lelieveld ${ }^{1,2}$ \\ ${ }^{1}$ Max Planck Institute for Chemistry, 55128 Mainz, Germany \\ ${ }^{2}$ The Cyprus Institute, 1645 Nicosia, Cyprus
}

\begin{abstract}
Heat waves in the eastern Mediterranean and Middle East can have large socioeconomic impacts. We apply a newly developed statistical framework, based on the extreme value theory, to study the characteristics of heat waves in the region during the period 1973-2010 using data from 15 measurement stations across the region. The analysis shows increasing trends in the highest daytime temperatures in the Persian Gulf region in summer. Increasing trends in the number of heat waves are found at all stations, whereas the maximum temperature during heat waves is found unchanged, implying no change in their intensity. Furthermore, no significant trends in the heat wave duration are observed. Return levels are calculated for the individual hot days and found to be very high in the Persian Gulf region.
\end{abstract}

KEY WORDS: Heat wave $\cdot$ Extreme value $\cdot$ Middle East $\cdot$ Mediterranean Resale or republication not permitted without written consent of the publisher

\section{INTRODUCTION}

Heat waves have gained considerable scientific attention recently due to their potentially devastating socioeconomic effects. Large impacts are expected with respect to public health (Koppe et al. 2004), energy supply (IPCC 2007, Förster \& Lilliestam 2010), water availability (Koch \& Vögele 2009), agriculture (Ferris et al. 1998), forestry and ecosystems (Moriondo et al. 2006), among others. Understanding these impacts is relevant not only for scientists, but also for all components of society.

The Middle East spans several climates zones, where the eastern part is Mediterranean, the northern part is considered to be subtropical while the Arabian Peninsula has a hyper-arid desert climate. Different climate zones are found in the various mountain areas. The region has among the hottest and driest conditions found in the world. Numerous heat records were broken in the Middle East in the summer of 2010 with temperatures reaching $52.0^{\circ} \mathrm{C}$ in Jeddah (WMO 2011). This heat wave caused unprecedented demand for electricity in Saudi Arabia, needed for air conditioning. As a result eight power plants in the country were forced to shut down, leaving several Saudi cities without power (Gulf News, June 22, 2010, 'Heatwave in Middle East no cause for panic'). In Israel, the year 2010 was the hottest on record, and average temperatures were $2-3^{\circ} \mathrm{C}$ higher than the average (Israel Meteorological Service 2011).

A large number of research papers focusing on extreme temperatures on global, regional and national scales have been published in the last 2 decades. Several global studies have been conducted using indices of climate extremes, provided by the Expert Team on Climate Change Detection and Indices (ETCCDI), mostly since the early works of Jones et al. (1999), Folland et al. (1999), Karl \& Easterling (1999) and Frich et al. (2002). More recently, the global work on extreme climatological variables, including temperature, has been updated by Alexander et al. (2006). Further, implications of climate warming for hot extremes have been investigated globally (Tebaldi 2007, Orlowsky 2011, Hansen et al. 2012, IPCC 2012) and regionally, 
e.g. in Europe (Christensen \& Christensen 2007, Fischer \& Schär 2010) and in the Mediterranean and the Middle East (Diffenbaugh et al. 2007, Gao \& Giorgi 2008, Evans 2009, Önol \& Semazzi 2009, Hertig et al. 2010, Lelieveld et al. 2013).

Few studies related to heat waves in this region could be found in the literature, mostly due to data unavailability. Trends of extreme temperatures in the eastern Mediterranean region have been evaluated by Kostopoulou \& Jones (2005), Kuglitsch et al. (2010) and Kostopoulou et al. (2014). Kostopoulou \& Jones (2005) showed that the most significant temperature trends were found for summer, where both minimum and maximum temperature extremes show statistically significant warming trends. Efthymiadis et al. (2011) used daily gridded data sets to detect trends in Mediterranean temperature extremes since the mid20 th century. Their results show a decrease in cold extremes and increase in hot extremes. Kuglitsch et al. (2010) have shown increases in the number, intensity and length of heat waves in the eastern Mediterranean. Tayanç et al. (2009) showed a significant warming trend in southern and southeastern parts of Turkey for the period 1950-2004. The only regional work with a focus on the Middle East is by Zhang et al. (2005), presenting changes in extreme temperature and precipitation at 52 stations from 15 countries for the period 1950-2003. Increasing trends have been found in the annual maximum of daily maximum and the number of days where daily temperature has exceeded its 90th percentile. Fewer studies on changes in climate extremes can be found for the Middle East, mainly due to the poor data network in Arab countries and limited access to long daily data sets. Recently, Donat et al. (2014) examined the temporal changes in climate extremes in the Arab region based on 60 stations from Arab countries collected during a workshop held in 2012. They found increased frequencies of warm days and warm nights and higher extreme temperature values. Athar (2014) used observed daily temperature and precipitation datasets from a total of 19 stations from Saudi Arabia (SA) for a 30 yr period (1979-2008) to calculate climate indices. Athar (2014) shows that temperature extremes display more warming in the summer season, with the southwest coastal stations displaying more warming as compared to the inland stations. Almazroui et al. (2014) show that the temperature extremes in Saudi Arabia have significantly increased with larger rates in the recent past (1996-2010) compared to a previous period (19811995). Other variability analyses are reported for extreme climate indices in Iran and Turkey (e.g. Rahimzadeh et al. 2009, Erlat \& Türkeş 2012, 2013,
Kousari et al. 2013). Kousari et al. (2013) found positive trends of annual, seasonal and monthly maximum temperature in the warm season of the period 1960-2005 for 32 stations in Iran with an increasing trend after 1970. Erlat \& Türkeş (2013) show increasing trends in the annual number of summer and tropical days of 97 meteorological stations of Turkey.

The descriptive indices developed by ETCCDI refer to moderate extremes that typically occur several times per year. The extreme value theory (EVT) complements the descriptive indices in order to evaluate the intensity and frequency of rare events. EVT provides the statistical framework to estimate the probability of occurrence of extreme or very rare events (Klein Tank et al. 2009). EVT methods generally use a subset of a large number of values from the data sample to infer the extreme characteristics of the underlying process that generate the phenomena (Coelho et al. 2008). Recently, several studies of climate extremes by means of the EVT have been published (e.g. Kharin \& Zwiers 2000, 2005, van den Brink et al. 2004, Fowler et al. 2005, Kharin et al. 2005, Naveau et al. 2005). Most of these studies use only one aspect of the EVT (the block maxima approach) and do not address heat waves directly. Katz (2010) and Furrer et al. (2010) proposed an EVT framework suitable to study heat waves and hot spells using 2 approaches: the block maxima approach and the peak-over-threshold (POT) approach. This study applies the proposed approaches to assess heat wave characteristics in the period 1973-2010. Our purpose is to apply the new EVT framework to study the frequency, intensity and duration of heat waves and their trends in the region of the eastern Mediterranean and Middle East.

\section{DATA AND METHODOLOGY}

Daily station data in the Middle East are difficult to obtain from the local meteorological services, therefore daily maximum temperature data extracted from the publicly available datasets are used in the study. Fifteen stations across the eastern Mediterranean and the Middle East (Fig. 1) have been chosen according to the availability and quality of the meteorological data for the historical period 1973-2010. The station locations represent the major climate zones in the region, notably near populated areas. A small portion of stations did not provide data for the complete period (see Table 1) or because of homogenization reasons, but still have been included. The data sources are the Global Summary Of The Day (GSOD: https://data. 


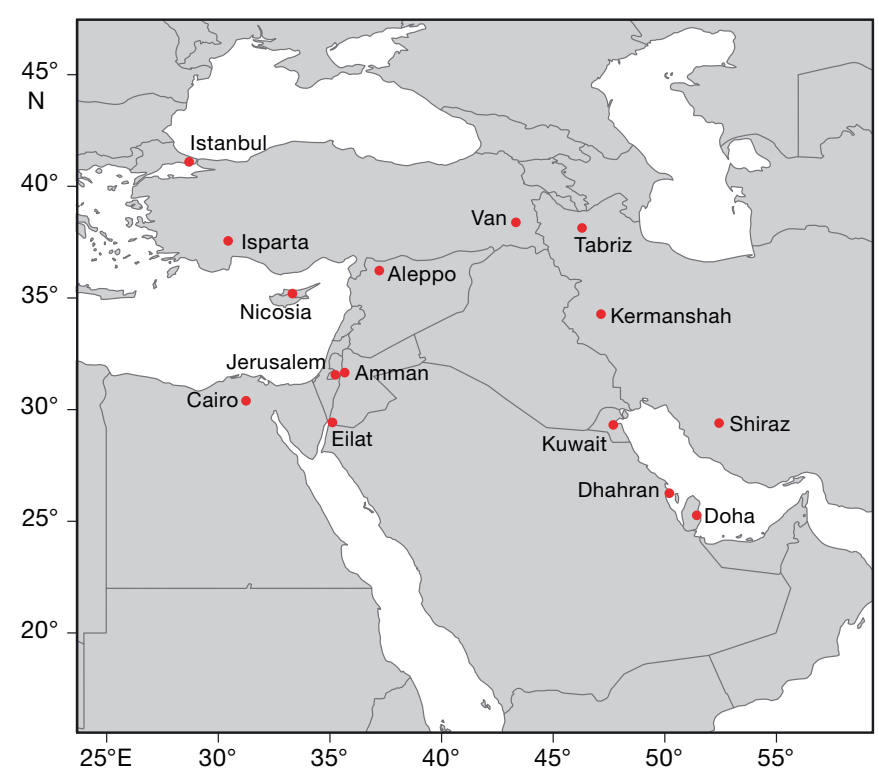

Fig. 1. The 15 stations across the eastern Mediterranean and the Middle East, used in this study

noaa.gov/dataset/global-surface-summary-of-the-daygsod) and ECA\&D (European Climate Assessment \& Datasets: www.ecad.eu).

The GSOD data, produced by the National Climatic Data Center (NCDC), are derived from the synoptic/hourly observations contained in USAF DATSAV3 Surface data, a collection of worldwide surface weather observations from sources such as the Global Telecommunications System (GTS) and Automated Weather Network (AWN). Historical data are generally available from 1973 to the present, with some stations having data going back to before 1930 . Generally, data from 1982 (beginning of current synoptic code) to the present are the most complete. In deriving the summary of the day data, a minimum of 4 observations for the day must be available.

The new ECA\&D dataset includes station series for 9 daily climate variables. The dataset comprises daily time series provided by the National Meteorological Services of countries in Europe, North Africa and the Middle East, augmented with data from other institutes and from earlier research projects (Klein Tank et al. 2002, Klok \& Klein Tank 2009). The data are extensively quality-checked and tested for homogeneity.

\subsection{Quality checks}

No further quality checks are applied to the ECA\&D stations used in this study. Only stations from GSOD are further quality-checked, although the synoptic data are already extensively tested to eliminate many of the random errors found in the original data. The RHtestV3 software (available from www.climdex.org, Wang 2008) has been used to eliminate possible additional errors. Less than $5 \%$ of errors were found, and a few physically implausible values have been set to missing; all stations have $>90 \%$ of records available.

\subsection{Homogenization}

Data homogeneity is assessed only for GSOD data using the RHtestV3 software, which uses a 2-phase regression model applied to monthly data in order to check for multiple step change points that could exist in a time series (Wang 2008). Significant change points $(5 \%$ level) were identified in 4 stations (Table 1). Most of the change points occur at the end of 1999/beginning of 1998, which concurs with similar findings by Peterson et al. (1998) and Alexander et al. (2006). These change points are apparently linked to hot weather events associated with the 1997-98 El Niño. This might also apply to the change point found in Amman in 1993. Historical explanations for the cause of the change points, such as station relocation, are not provided by GSOD, and our requests to the national meteorological services of these stations remained unanswered. Therefore, no adjustment of the time series of these stations has been possible.

\subsection{Extreme value theory}

The EVT is the area of statistics used specifically to analyze extreme events. In this study, 2 methods derived from EVT are used to analyze heat waves and their characteristics (e.g. frequency and intensity).

\subsubsection{The block maxima approach}

The first approach, the block maxima approach is used to analyze data to be the maxima (or minima) over certain blocks of time. In this context, it is appropriate to use the generalized extreme value (GEV) distribution, a distribution derived from EVT. In this approach the time series are constructed by determining the maximum temperature for the summer season (here taken from the first of June to first of November), so the length of the series equals the number of years for which data is available. 
Table 1. Station list and number of change points identified for each station. Only GSOD stations have been checked for multiple change points

\begin{tabular}{|lcccccc|}
\hline Station & Source & Country & Latitude & Longitude & Period & Change points \\
\hline Aleppo & GSOD & Syria & $36^{\circ} 13^{\prime} \mathrm{N}$ & $37^{\circ} 10^{\prime} \mathrm{E}$ & $1973-2010$ & $0 \mathrm{CP}$ \\
Amman & GSOD & Jordan & $31^{\circ} 56^{\prime} \mathrm{N}$ & $35^{\circ} 55^{\prime} \mathrm{E}$ & $1973-2010$ & $1 \mathrm{CP}: 199305$ \\
Cairo & GSOD & Egypt & $30^{\circ} 03^{\prime} \mathrm{N}$ & $31^{\circ} 13^{\prime} \mathrm{E}$ & $1973-2010$ & 0 CP \\
Dhahran & GSOD & Saudi Arabia & $26^{\circ} 16^{\prime} \mathrm{N}$ & $50^{\circ} 09^{\prime} \mathrm{E}$ & $1973-2005$ & $1 \mathrm{CP}: 200511$ \\
Doha & GSOD & Qatar & $25^{\circ} 17^{\prime} \mathrm{N}$ & $51^{\circ} 32^{\prime} \mathrm{E}$ & $1973-2010$ & $1 \mathrm{CP}: 199801$ \\
Eilat & ECA-D & Israel & $29^{\circ} 33^{\prime} \mathrm{N}$ & $34^{\circ} 57^{\prime} \mathrm{E}$ & $1973-2010$ & - \\
Jerusalem & ECA-D & Israel & $31^{\circ} 46^{\prime} \mathrm{N}$ & $35^{\circ} 13^{\prime} \mathrm{E}$ & $1973-2004$ & - \\
Isparta & ECA-D & Iran & $37^{\circ} 46^{\prime} \mathrm{N}$ & $30^{\circ} 33^{\prime} \mathrm{E}$ & $1973-2010$ & - \\
Istanbul & GSOD & Turkey & $41^{\circ} 00^{\prime} \mathrm{N}$ & $28^{\circ} 58^{\prime} \mathrm{E}$ & $1973-2010$ & $1 \mathrm{CP}: 199712$ \\
Kermanshah & ECA-D & Iran & $34^{\circ} 18^{\prime} \mathrm{N}$ & $47^{\circ} 03^{\prime} \mathrm{E}$ & $1973-2008$ & - \\
Kuwait City & GSOD & Kuwait & $29^{\circ} 22^{\prime} \mathrm{N}$ & $47^{\circ} 58^{\prime} \mathrm{E}$ & $1973-2010$ & $0 \mathrm{CP}$ \\
Nicosia & ECA-D & Cyprus & $35^{\circ} 10^{\prime} \mathrm{N}$ & $33^{\circ} 21^{\prime} \mathrm{E}$ & $1973-2009$ & - \\
Shiraz & ECA-D & Iran & $29^{\circ} 30^{\prime} \mathrm{N}$ & $52^{\circ} 32^{\prime} \mathrm{E}$ & $1973-2009$ & - \\
Tabriz & ECA-D & Iran & $38^{\circ} 04^{\prime} \mathrm{N}$ & $46^{\circ} 18^{\prime} \mathrm{E}$ & $1973-2009$ & - \\
Van & ECA-D & Turkey & $38^{\circ} 29^{\prime} \mathrm{N}$ & $43^{\circ} 22^{\prime} \mathrm{E}$ & $1973-2010$ & - \\
\hline
\end{tabular}

In this approach the model focuses on the statistical behavior of

$$
M_{n}=\max \left\{X_{1} ; X_{2} ; \ldots ; X_{n}\right\}_{;}
$$

where $X_{1}, X_{2}, \ldots, X_{\mathrm{n}}$ is a sequence of independent random variables having a common distribution function $F$. In the context of this work, the $X_{i}$ stands for values of the daily extreme temperature process and $M_{n}$ represents the maximum of the process over $n$ time units of observation. For instance, if $n$ is the number of observations over the summer season in a year, then $M_{n}$ is the annual summer maximum. The distribution function is:

$$
\begin{aligned}
\operatorname{Pr}\left\{M_{n} \leq z\right\} & =\operatorname{Pr}\left\{X_{1} \leq z, \ldots, X_{n} \leq z\right\} \\
& =\operatorname{Pr}\left\{X_{1} \leq z\right\} \times \operatorname{Pr}\left\{X_{2} \leq z\right\} \times . . \times \operatorname{Pr}\left\{X_{n} \leq z\right\} \\
& =\{F(z)\}^{n}
\end{aligned}
$$

As argued in Leadbetter et al. (1983), the distribution of the maximum of identically distributed random variables is well approximated by the GEV distribution, with three parameters: a location parameter $\mu$, a scale parameter $\sigma$, and a shape parameter $\xi$.

$$
F(z, \mu, \sigma, \xi)=\exp \left\{-\left[1+\xi\left(\frac{z-\mu}{\sigma}\right)\right]^{-1 / \xi}\right\}
$$

defined on $\left\{z: 1+\xi\left(\frac{z-\mu}{\sigma}\right)>0\right\}$, where $-\infty<\mu<\infty$, $\sigma>$ 0 and $-\infty<\xi<\infty$.

The location parameter $\mu$ and the scale parameter $\sigma$ are respectively, proportional to the mean and the variance of extremes, while the shape parameter $\xi$ describes the shape of the tail $(\xi<0$ implies that it admits a right bound $z_{p}=\mu-\sigma / \xi, \xi>0$ describes a left bounded tail, with the same bound, and $\xi=0$ gilts for an unbounded tail, known as Gumbel distribution.

\subsubsection{The peak-over-threshold approach}

The POT approach provides a model for independent exceedances above a large threshold. Assuming that exceedances are independent, identically distributed random variables, the distribution of exceedances asymptotes to a limit distribution, the generalized Pareto distribution (GPD). For more details, see Coles (2001), p. 76.

Thus, the GPD can be used to model exceedances above a given threshold. This distribution can be written in terms of a generic variable $x$ as:

$$
G(x)=1-\left[1+\xi\left(\frac{x-\mu}{\sigma}\right)\right]^{-1 / \xi} \quad(x>u, \xi \neq 0)
$$

The GPD function is a so-called cumulative distribution function, so it can be expressed in terms of probabilities. Let $\mathrm{X}$ be an independent and identically distributed random variable of the GPD function. Then Eq. 4 can be rewritten as follows:

$$
\begin{gathered}
\operatorname{Pr}(X<x, x>u)=G(x) \\
\operatorname{Pr}(X>x, x>u)=1-G(x) \\
\operatorname{Pr}(X>x)=\operatorname{Pr}(x>u)[1-G(x)] \\
\operatorname{Pr}(X>x)=\zeta u\left[1+\xi\left(\frac{x-\mu}{\sigma}\right)\right]^{-1 / \xi}
\end{gathered}
$$

where $\zeta_{u}=\operatorname{Pr}(\mathrm{X}>u)$, i.e. $\zeta_{u}$ is the probability of the occurrence of an exceedance of a high threshold, $u$. 
The GPD is characterized by two parameters, $\xi$ the shape parameter and $\sigma$ the scale parameter. The shape parameter determines the tail behaviour: if $\xi>$ 0 then the maximum of the GPD is unbounded, whereas if $\xi<0$ then the tail has a finite extent. If $\xi=$ 0 , the GPD reduces to the exponential distribution and is also unbounded in the limit $\xi \rightarrow 0$. As for the scale parameter, it measures the scale or 'amplitude' of the distribution.

Under the framework of the second approach, the POT approach, the extreme temperature series is made up of the values above a threshold regardless of the year in which they occurred. The selection of a threshold is not simply related to the spatial variability of the heat wave characteristics in our domain. In this study, the 95th percentile of the time series is selected as a temperature threshold that must be crossed to start and end a heat wave. The heat wave as defined here is not necessarily equivalent to the extremely hot weather event from the societal point of view. This approach is used to study the frequency of high temperature clusters and the maximum intensity within clusters, measured by the highest temperature observed in each cluster. The frequency of high temperature clusters per year is analyzed and fitted using a Poisson distribution (PD); the maximum intensity within a cluster for each city was analyzed and fitted to a GPD.

A likelihood-ratio test is a statistical test used to compare the fit of 2 models, one of which (the null model) is a special case of the other (the alternative model). The test is based on the likelihood ratio, which expresses how many times more likely the data are under one model than the other. In this context, we will be comparing fitted distributions with and without trends.

For more details about the EVT approaches, see Coles (2001). Our analysis follows the methodology recommended by Furrer et al. (2010), Katz (2010) and Walter (2008), and uses the extRemes package in the open source statistical programming language $\mathrm{R}$ (www.cran.r-project.org/web/packages/extRemes/) (Stephenson \& Gilleland 2006).

\section{RESULTS}

\subsection{General statistics}

Table 2 shows some basic statistics for the time series of the maximum temperature in the summer season. The highest temperatures are found in Kuwait City, followed by Dhahran. Van and Isparta
Table 2. Basic statistics of Tmax for the 15 stations

\begin{tabular}{|lccccc|}
\hline Station & Mean & Median & Min & Max & STD \\
\hline Aleppo & 42.35 & 42.14 & 38.50 & 48.28 & 2.41 \\
Amman & 39.49 & 39.25 & 36.00 & 43.40 & 1.77 \\
Cairo & 42.42 & 42.10 & 39.40 & 45.20 & 1.52 \\
Dhahran & 48.10 & 48.00 & 46.00 & 51.00 & 1.33 \\
Doha & 47.26 & 47.11 & 44.00 & 50.39 & 1.22 \\
Eilat & 44.84 & 32.00 & 42.80 & 47.40 & 1.12 \\
Jerusalem & 36.66 & 36.75 & 32.80 & 40.80 & 1.79 \\
Isparta & 35.73 & 35.60 & 33.00 & 38.70 & 1.38 \\
Istanbul & 35.29 & 35.00 & 32.00 & 40.00 & 2.01 \\
Kermanshah & 41.90 & 42.10 & 39.80 & 44.10 & 1.22 \\
Kuwait City & 49.57 & 50.00 & 46.00 & 51.28 & 1.08 \\
Nicosia & 41.81 & 41.60 & 39.60 & 44.20 & 1.17 \\
Shiraz & 41.06 & 41.00 & 38.20 & 43.20 & 0.96 \\
Tabriz & 38.48 & 38.40 & 35.60 & 41.00 & 1.24 \\
Van & 32.69 & 32.60 & 29.50 & 37.00 & 1.67 \\
\hline
\end{tabular}

have the relatively lowest temperatures, both situated $>1000 \mathrm{~m}$ above sea level. Only limited local variability is observed, except for Aleppo and Istanbul with a standard deviation of $>2$ and a large difference between the minimum and the maximum value.

\subsection{Block maxima approach}

The block maxima approach is used to analyze the annually highest summer temperatures at all stations (see Fig. A1 in the Appendix). Fig. 2 shows the highest summer temperatures with trend lines for the 50 and $90 \%$ quantile. Quantile regression is the analysis method estimating the regression slopes for the values of any quantile from 0 to 1 of dependent variable distributions (Koenker \& Bassett 1978). Moreover, it provides a detailed picture of the conditional distribution of the dependent variable (Tmax) given the independent variable (Time) when both lower and upper or all quantiles are of interest; hence it is especially useful in applications where extremes are important. Dhahran, Doha, Isparta and Kuwait show significant tendencies for the $50 \%$ quantile trend with an increase of respectively $0.6,0.2,0.5$ and $0.3^{\circ} \mathrm{C}$ per decade.

The likelihood-ratio test is performed to determine whether a GEV model with a linear trend significantly improves the fit over a model that does not consider a trend. The p-values shown in Fig. 2 for each station reflect no strong evidence that the highest maximum temperatures vary over time for most of stations except for Dhahran, Doha, Isparta and Kuwait.

No significant trends were observed for the $90 \%$ quantile, despite large increases observed in Aleppo, 
Aleppo

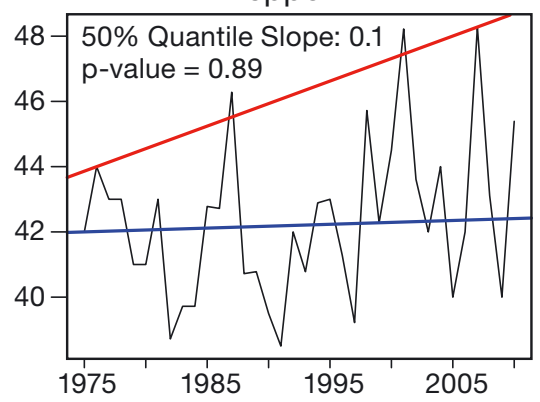

Amman
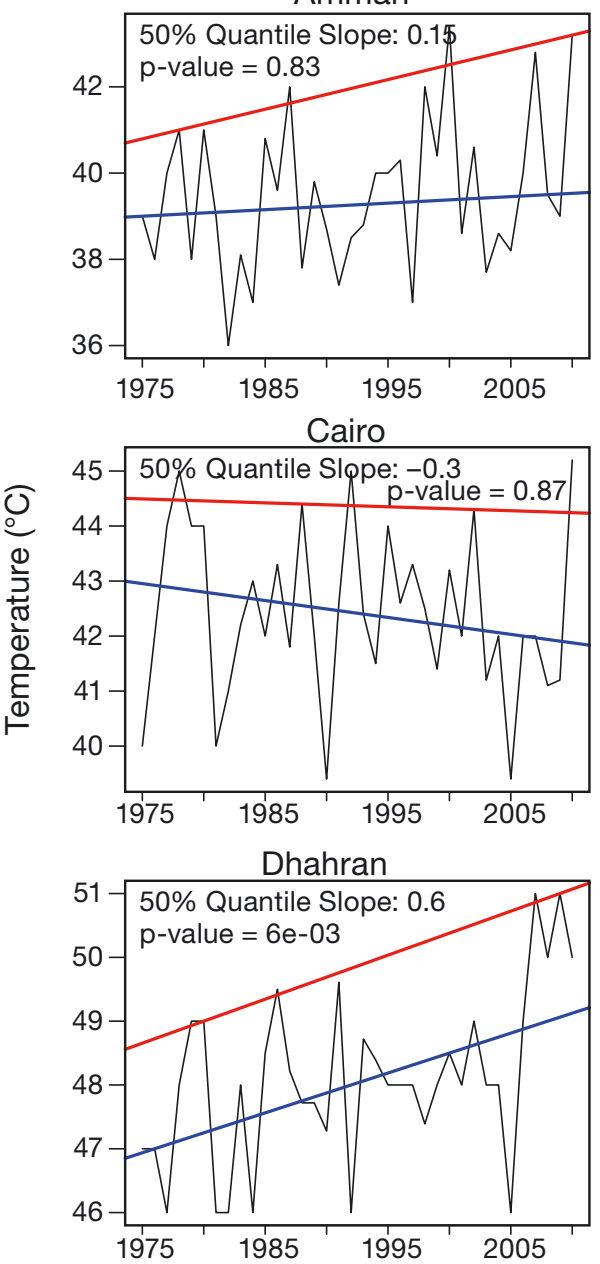

Doha

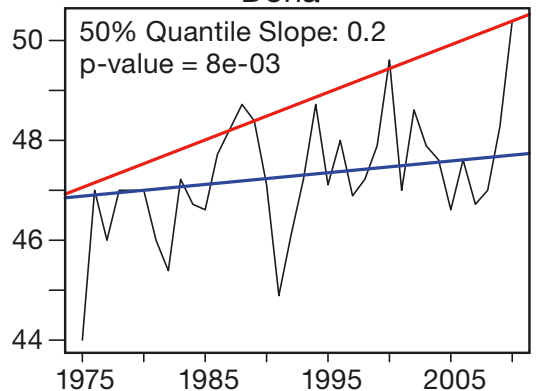

Eilat

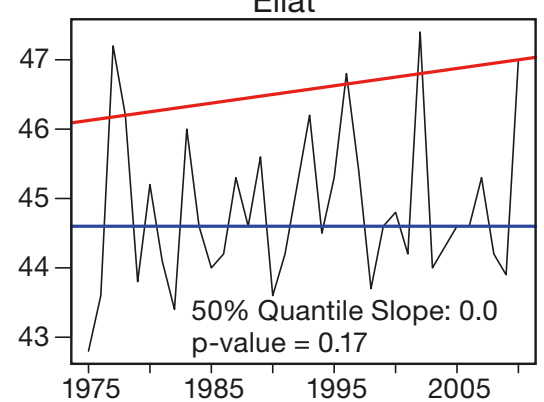

Isparta

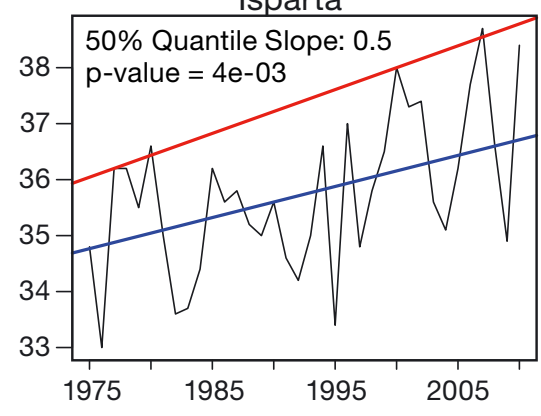

Istanbul

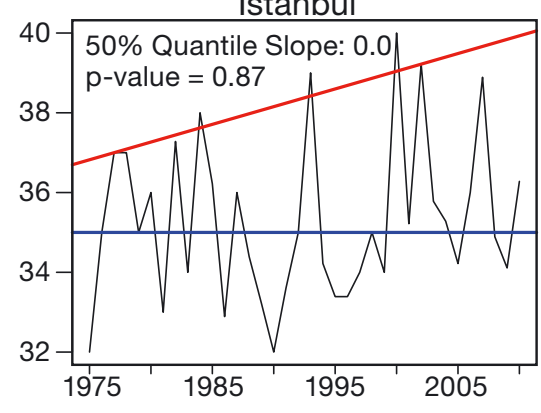

Jerusalem

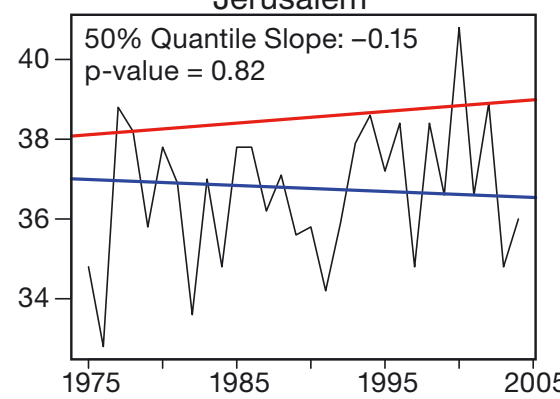

Kermanshah

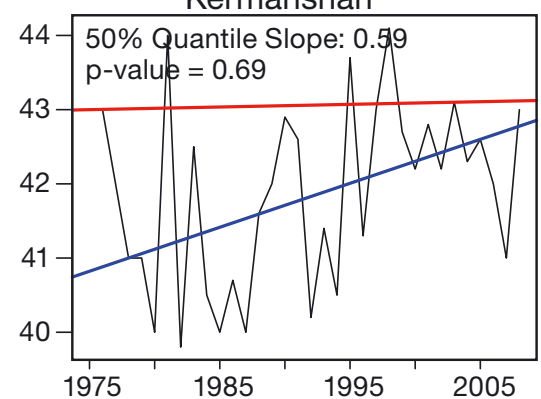

Kuwait

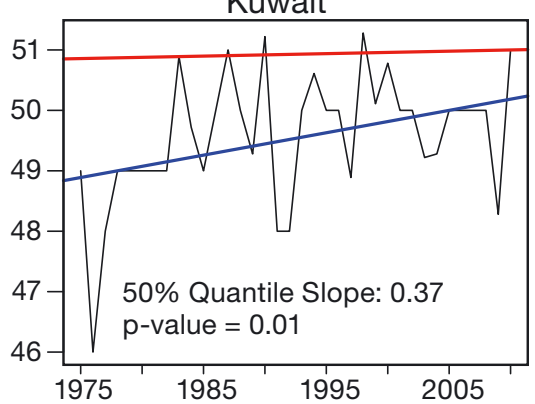

Nicosia

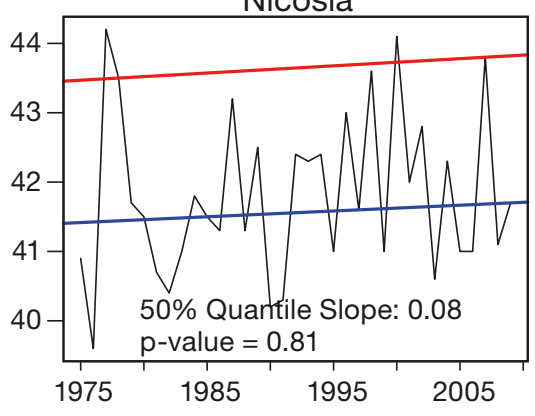

Shiraz

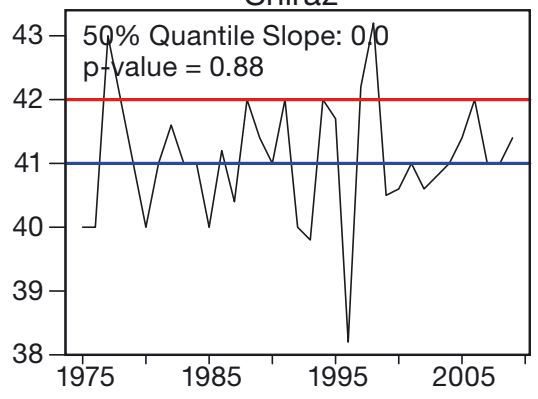

Tabriz
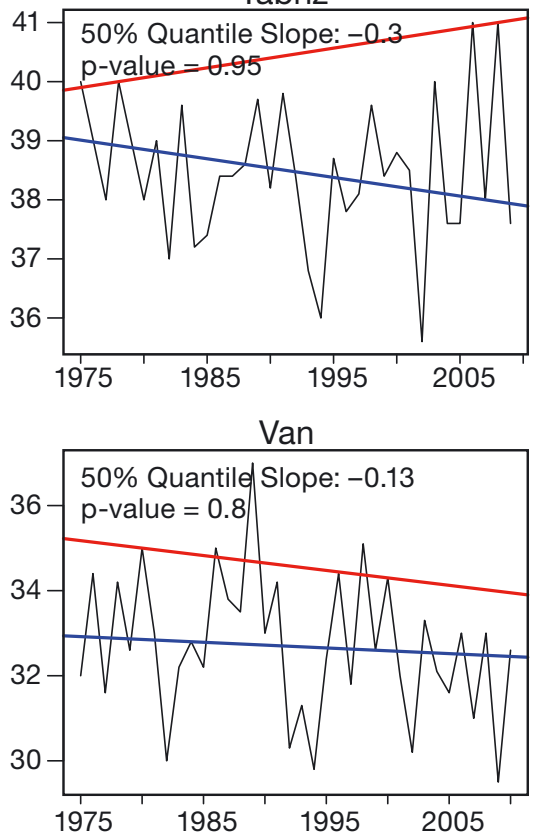

Fig. 2. Time series of the annually highest summer temperatures using the block maxima approach with trend lines for the $50 \%$ quantile (blue) and $90 \%$ quantile (red). The p-values are calculated for the likelihood-ratio test against the null model of no trend 
Amman, Dhahran, Doha, Isparta and Istanbul. The 2 quantiles tend to converge only in Kuwait, Kermanshah and Van.

Although the trends in the annual highest summer temperature have been derived for individual exceptionally hot days, they suggest that trends might exist also for heat waves, which motivates further investigation of the characteristics of the consecutive hot days that may occur.

\subsection{Peak-over-threshold approach}

This approach is used to analyze the frequency of the high temperature clusters and the maximum intensity within clusters. In this study, a cluster is defined by temperatures exceeding the threshold of the 95th percentile of the time series for one day, and then falling below the threshold.

Fig. 3 shows the number of clusters per year fitted to a PD. Statistically significant trends were found for all cities except for Aleppo, Amman, Nicosia, Tabriz and Van. The likelihood-ratio test against the null model of no trend performed for each station gives very low p-values for significant trends, as seen in the figure. Drastic increases in the mean number of clusters over the course of $37 \mathrm{yr}$ are observed in Cairo (from 4 to 9), Dhahran (from 1 to 10), Isparta (from 2 to 6), Istanbul (from 2 to 8) and Kuwait (from 1 to 5).

Further, the severity of the heat waves is assessed using the highest daily maximum temperature within a cluster in Fig. 4. The trends in the 2 quantiles (50 and $75 \%$ ) of the fitted GPD distributions (see Fig. A2) are shown with no significant trend using the likelihood-ratio test in most of the cities, with the exception of Dhahran and Isparta. More apparent decreasing trends are found for the $75 \%$ quantile trend in Cairo, Eilat, Istanbul, Kermanshah, Shiraz and Tabriz. This indicates that the mean trend of the maximum temperature within a cluster may be influenced more by the upper than the lower quantiles.

Fig. 5 shows the duration of the heat waves as observed in all stations with quantile regressions for 50 and $90 \%$ implying the trends. No significant trends can be derived from the median quantile, as the mean length of a heat wave in all stations varies between 1 and $2 \mathrm{~d}$. The $90 \%$ quantile shows an upward trend in Aleppo, Dhahran, Isparta, Istanbul, Kermanshah and Shiraz and a downward trend for Kuwait, Tabriz and Van. The $90 \%$ quantile trend implies that extended heat waves have increased or decreased in number over the time period considered, although the median values remained the same.

\subsection{Return levels}

Fig. A1 in the Appendix shows the histograms for the highest maximum temperatures in summer and their GEV distributions. Although deviations from the estimated probability function are apparent, the general shape of the histograms does not contradict the GEV assumption.

Table 3 shows maximum likelihood estimates of the GEV parameters at all stations, which includes standard errors for all estimates. Return values are estimated from the GEV distribution fitted for each time series, which enables the evaluation of rare events, such as the maximum temperatures that are exceeded on average every 10, 20 and $50 \mathrm{yr}$, i.e. return level at 10, 20 and 50 yr. Due to the relatively short time series, return levels for very long return lyperiods are prone to errors (Kharin et al. 2007).

The high temperature of $50^{\circ} \mathrm{C}$ is expected to be exceeded every $20 \mathrm{yr}$ in Dhahran, and every $10 \mathrm{yr}$ in Kuwait, $48^{\circ} \mathrm{C}$ every $10 \mathrm{yr}$ in Doha and $46^{\circ} \mathrm{C}$ every $10 \mathrm{yr}$ in Eilat. It should be noted that the confidence intervals are comparatively wider for certain stations such as Aleppo and Amman for RL20 and RL50.

\section{DISCUSSION AND CONCLUSIONS}

This study applies different concepts of EVT to characterize heat waves in the region of the eastern Mediterranean and Middle East. Due to the scarcity of reliable and available data, only 15 stations have been used to explore these characteristics, focusing on main urbanized areas. They span several climate zones, and different definitions of heat waves can be applied, which make these locations interesting to study. Moreover, in the absence of metadata available for the 3 GSOD stations presenting significant change points (see Table 1), we assumed that these change points could be attributed to climatic events. This might be equally related to the accuracy of measurement for each station in different time periods or other non-climatic factors affecting the data quality. Despite the inhomogeneities found in these stations, they were kept in the analysis because of the lack of gaps and the relatively good quality of the time series. These inhomogeneities might have affected the final results. Our data sources do not guarantee the best quality for the data provided, and no correction of inhomogeneities is possible without metadata. More meteorological data at stations throughout the region with better quality are needed for a full assessment of heat 

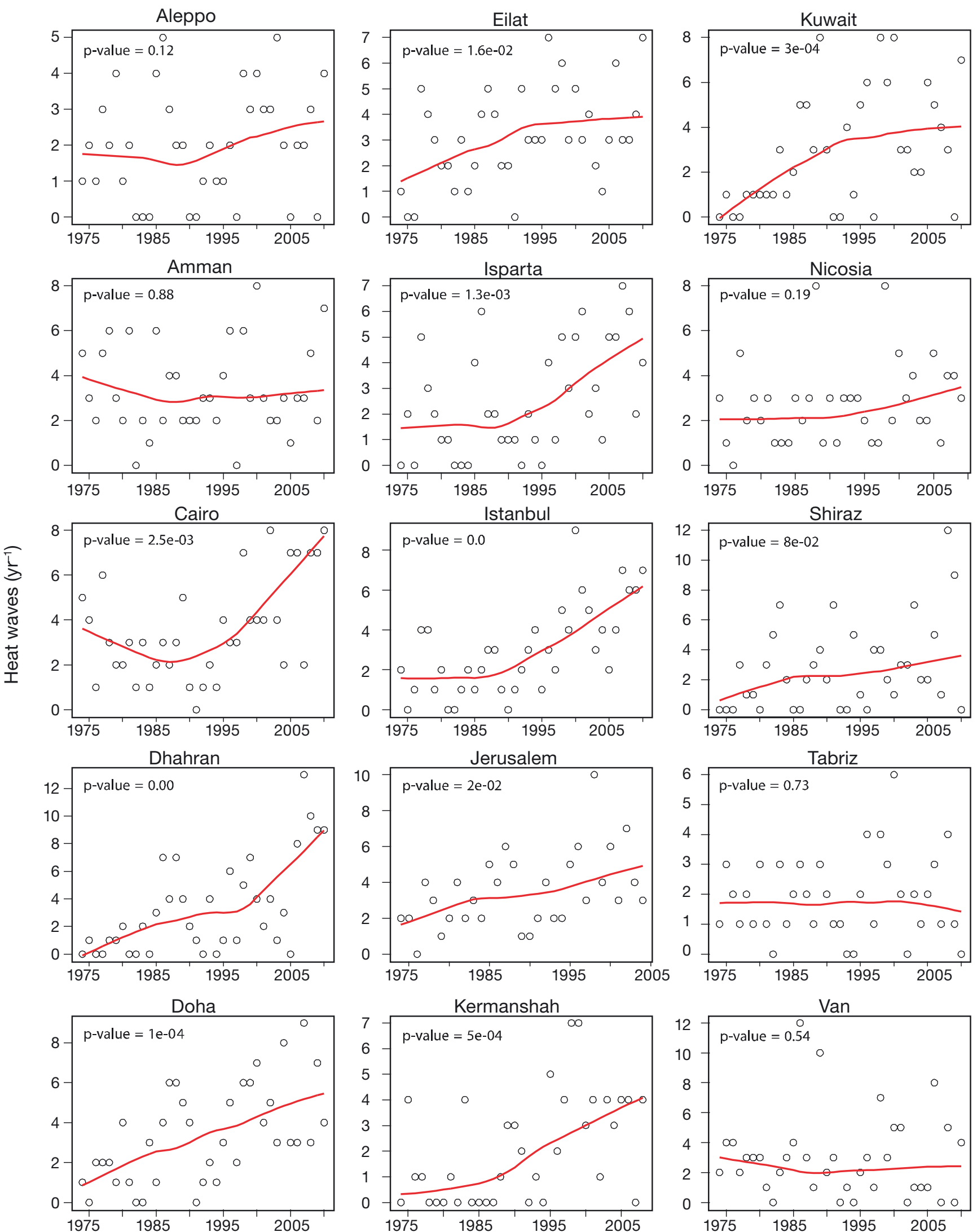

Fig. 3. Number of clusters (heat waves) per year. The red line depicts the trend in clusters based on a threshold of 95th percentile, using the locally weighted scatterplot smoothing curve (LOWESS). P-values are produced from the likelihood-ratio test against the null model of no trend 


\section{Aleppo}

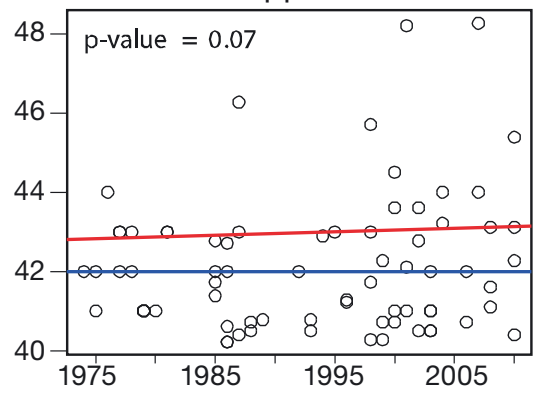

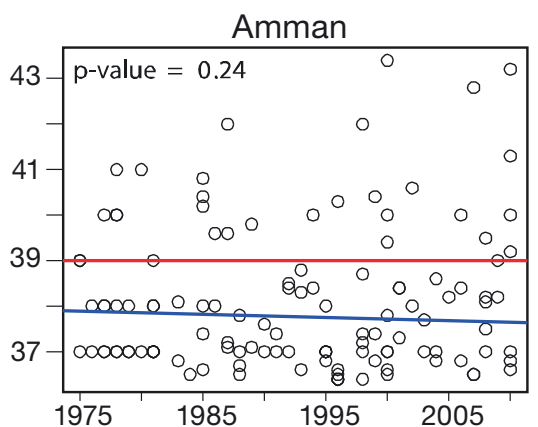

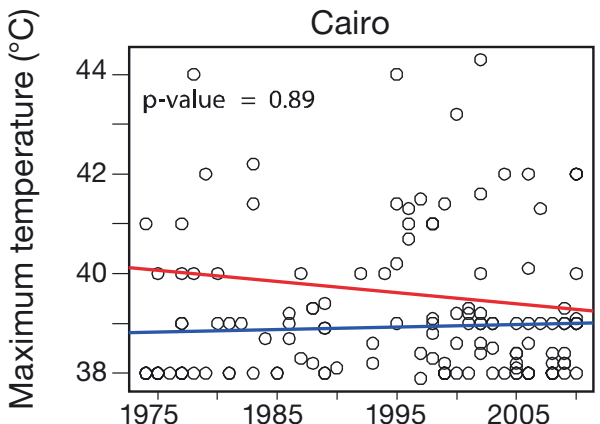

Dhahran
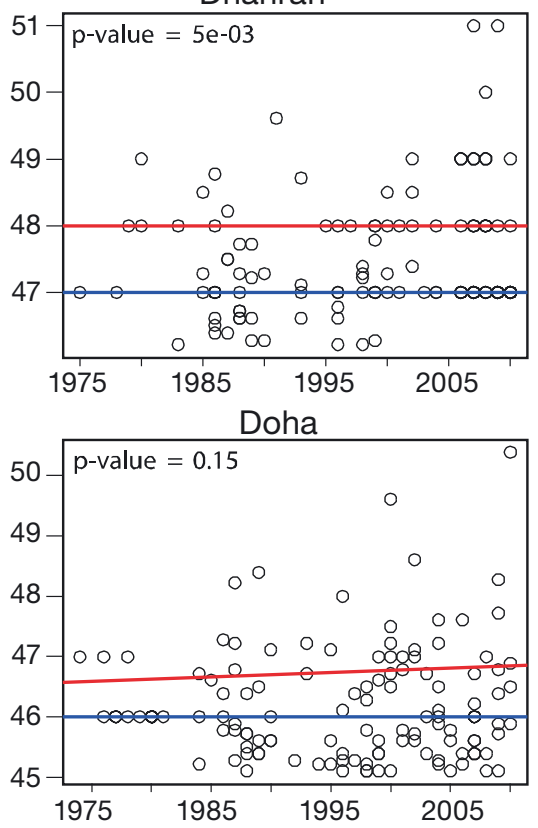

Eilat

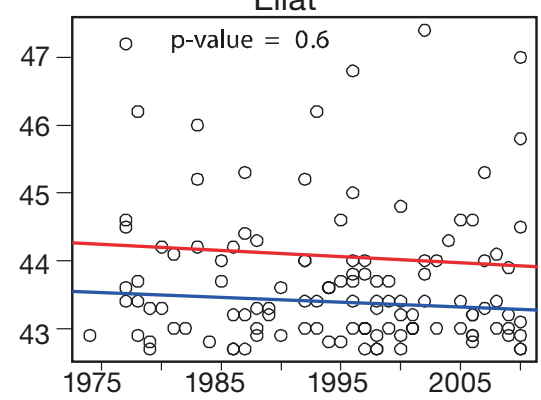

Isparta
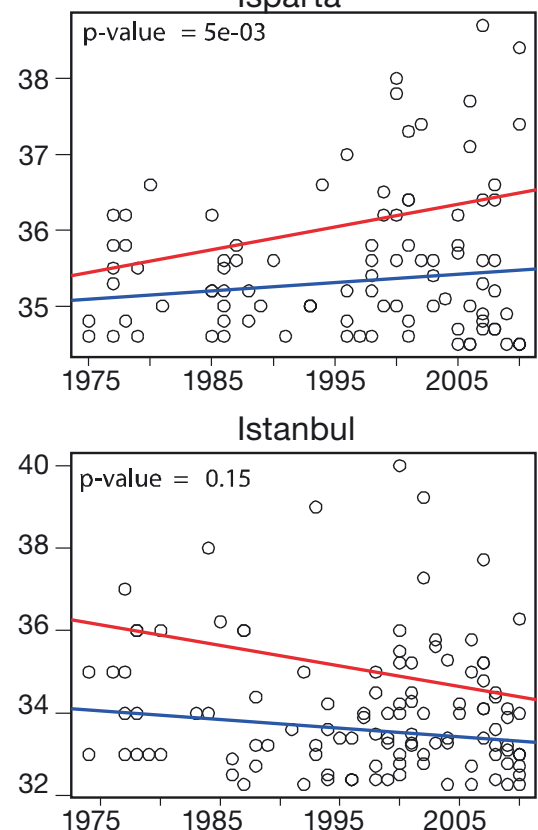

Jerusalem
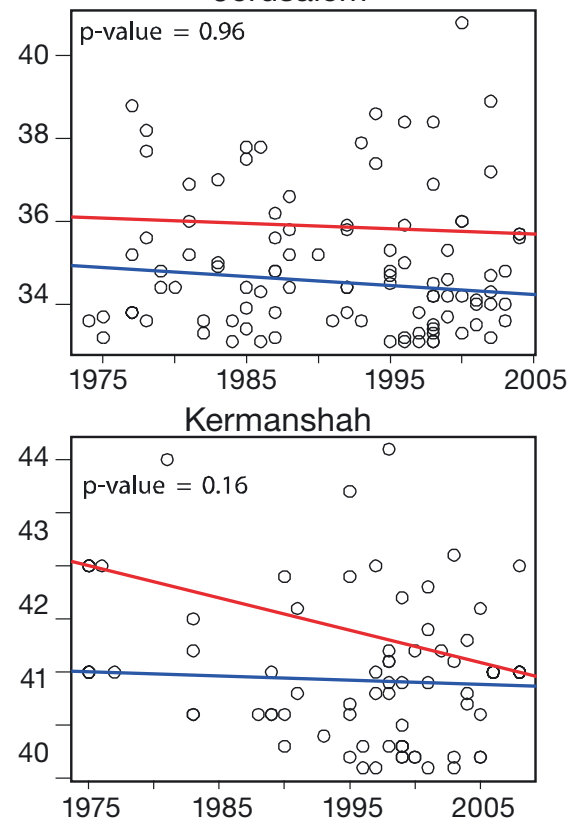

Kuwait

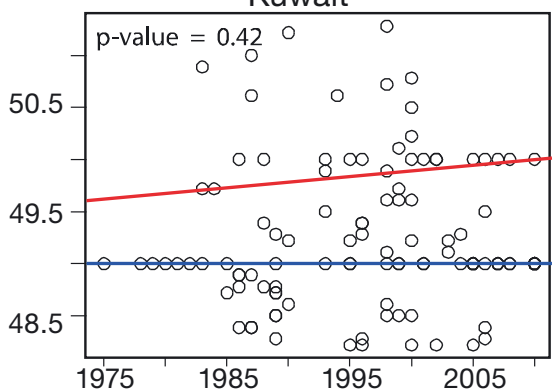

Nicosia

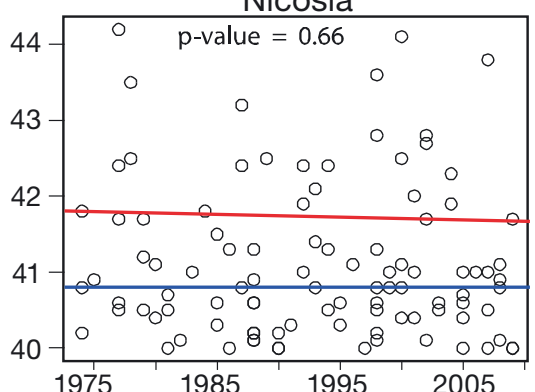

\begin{tabular}{ll|l|l|l}
1975 & 1985 & 1995 & 2005
\end{tabular}

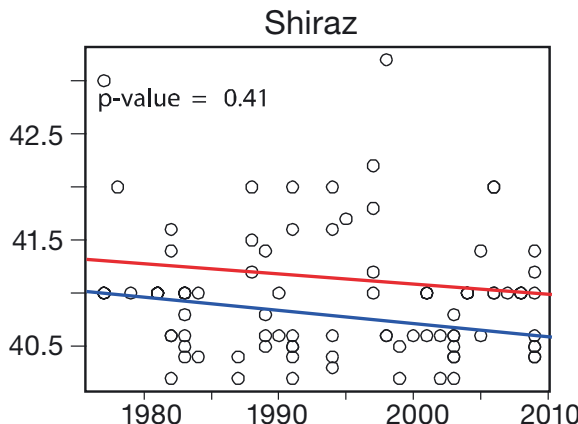

Tabriz
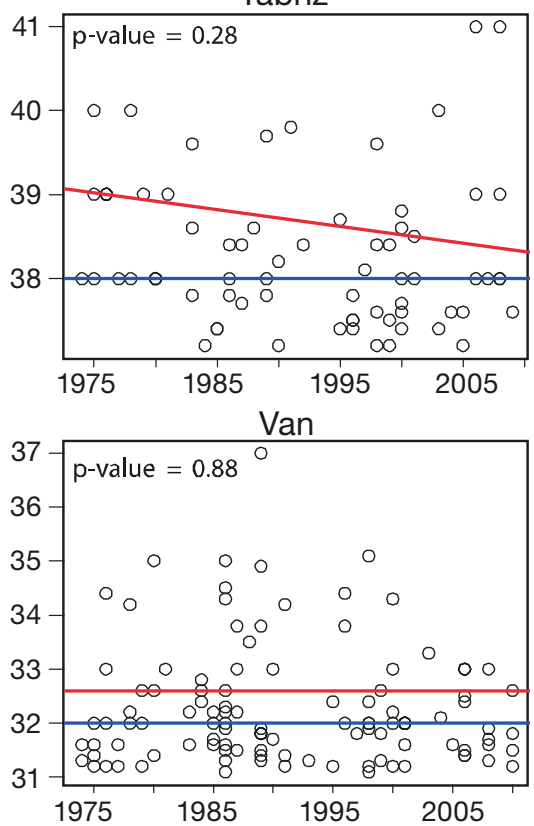

Fig. 4. Maximum temperature within clusters with trend lines for the $50 \%$ quantile (blue) and $75 \%$ quantile (red) 
Aleppo

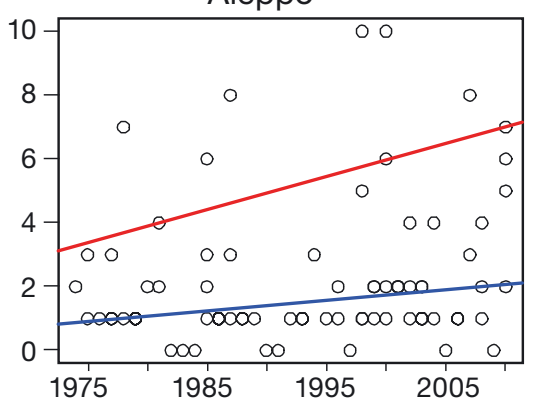

Amman

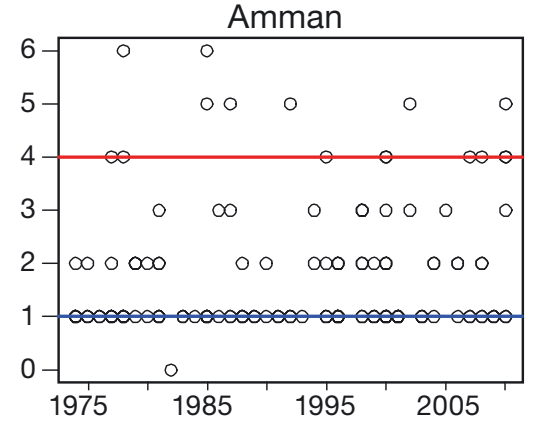

Cairo

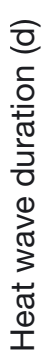

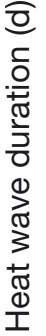
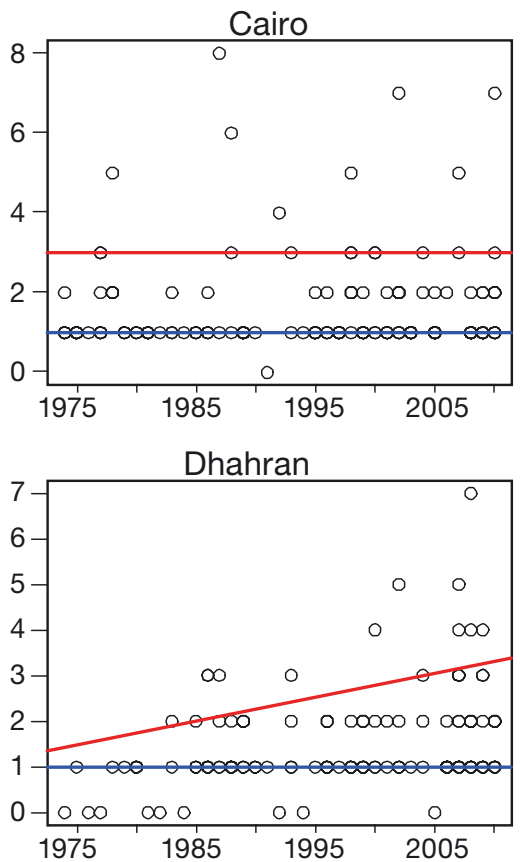

Doha

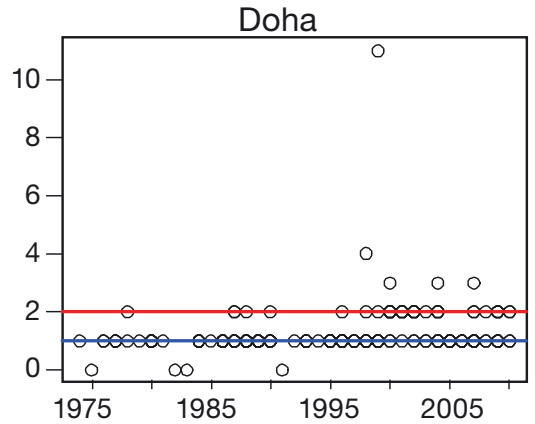

Eilat

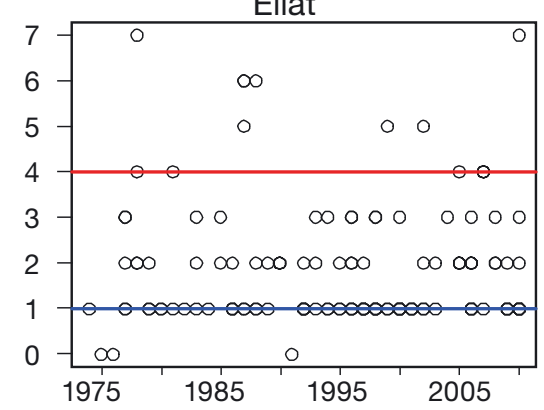

Isparta

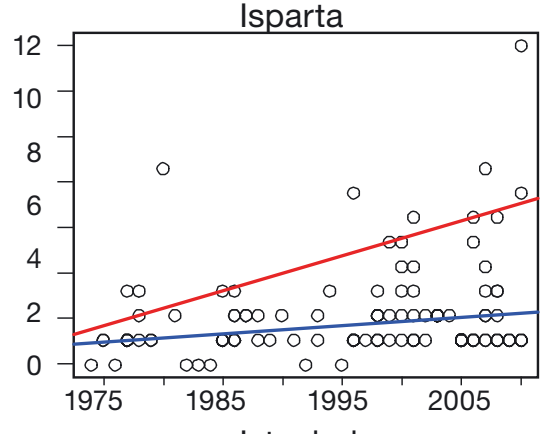

Istanbul

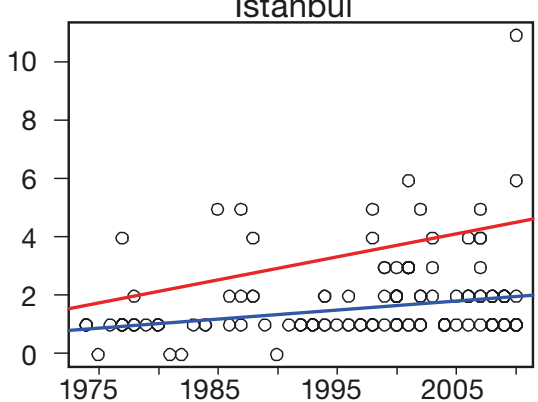

Jerusalem

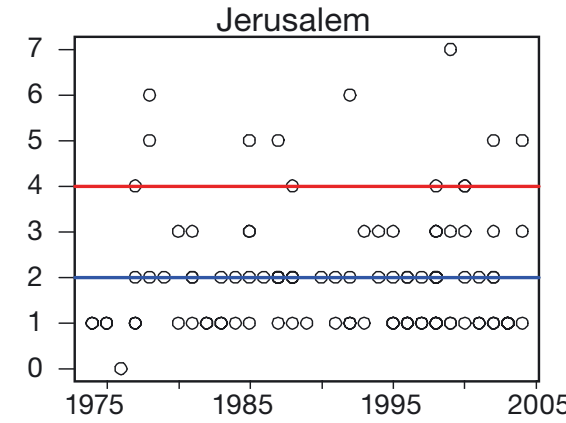

Kermanshah

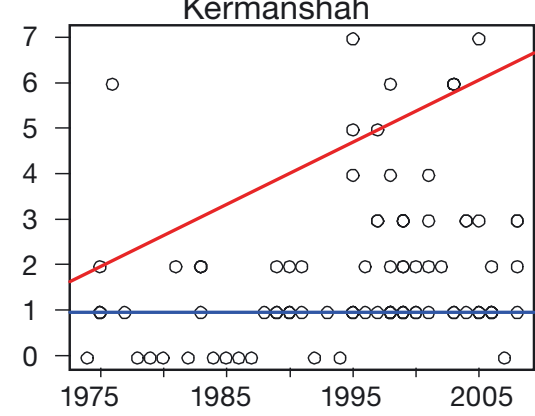

Kuwait
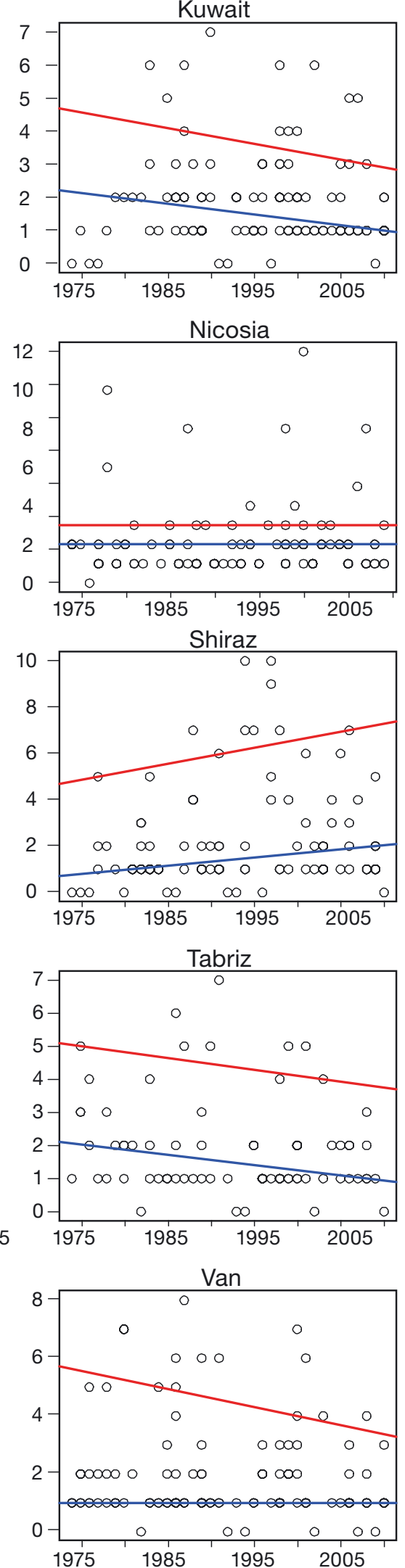

Fig. 5. Heat wave duration in days for all stations with trend lines for the $50 \%$ quantile (blue) and $90 \%$ quantile (red) 
Table 3. Estimates of the generalized extreme value (GEV) parameters with their standard errors, and return level (RL) values at 10, 20 and $50 \mathrm{yr}$ with their $95 \%$ confidence intervals (in parentheses) for all stations $\left({ }^{\circ} \mathrm{C}\right.$ )

\begin{tabular}{|c|c|c|c|c|c|c|}
\hline \multirow[t]{2}{*}{ Station } & \multicolumn{3}{|c|}{ GEV parameters } & \multirow[t]{2}{*}{ RL10 } & \multirow[t]{2}{*}{ RL20 } & \multirow[t]{2}{*}{ RL50 } \\
\hline & Location $\mu$ & Scale $\sigma$ & Shape $\zeta$ & & & \\
\hline Aleppo & $41.50 \pm 0.32$ & $1.72 \pm 0.24$ & $0.009 \pm 0.13$ & $45.50(44.09-46.91)$ & $46.68(44.55-48.81)$ & $48.34(44.92-51.77)$ \\
\hline Amman & $38.78 \pm 0.29$ & $1.58 \pm 0.21$ & $0.15 \pm 0.12$ & $41.79(40.89-42.70)$ & $42.55(41.37-43.73)$ & $43.42(41.72-45.12)$ \\
\hline Cairo & $41.94 \pm 0.28$ & $1.54 \pm 0.21$ & $0.35 \pm 0.13$ & $44.32(43.77-44.86)$ & $44.75(44.13-45.37)$ & $45.17(44.35-45.99)$ \\
\hline Dhahran & $47.60 \pm 0.23$ & $1.28 \pm 0.16$ & $0.23 \pm 0.11$ & $49.84(49.24-50.43)$ & $50.33(49.62-51.04)$ & $50.86(49.91-51.81)$ \\
\hline Doha & $46.82 \pm 0.22$ & $1.24 \pm 0.14$ & $0.26 \pm 0.07$ & $48.92(48.41-49.44)$ & $49.37(48.79-49.94)$ & $49.83(49.15-50.51)$ \\
\hline Eilat & $44.35 \pm 0.17$ & $0.91 \pm 0.12$ & $0.049 \pm 0.13$ & $46.30(45.62-46.97)$ & $46.88(45.93-47.82)$ & $47.60(46.14-49.06)$ \\
\hline Jerusalem & $36.04 \pm 0.35$ & $1.77 \pm 0.24$ & $0.28 \pm 0.10$ & $38.99(38.19-39.78)$ & $39.60(38.71-40.48)$ & $40.22(39.14-39.14)$ \\
\hline Isparta & $35.22 \pm 0.24$ & $1.32 \pm 0.17$ & $0.24 \pm 0.12$ & $37.51(36.90-38.12)$ & $38.01(37.27-38.75)$ & $38.55(37.53-39.56)$ \\
\hline Istanbul & $34.42 \pm 0.31$ & $1.68 \pm 0.23$ & $0.074 \pm 0.13$ & $37.90(36.73-39.08)$ & $38.90(38.90-40.54)$ & $40.11(37.60-42.63)$ \\
\hline Kermanshah & $41.55 \pm 0.24$ & $1.26 \pm 0.18$ & $0.40 \pm 0.13$ & $43.40(43.00-43.81)$ & $43.72(43.29-44.14)$ & $44.01(43.48-44.53)$ \\
\hline Kuwait City & $49.34 \pm 0.21$ & $1.17 \pm 0.16$ & $0.56 \pm 0.11$ & $50.84(50.59-51.10)$ & $51.04(50.81-51.27)$ & $51.20(50.96-51.45)$ \\
\hline Nicosia & $41.33 \pm 0.20$ & $1.03 \pm 0.14$ & $0.14 \pm 0.149$ & $43.31(42.69-43.94)$ & $43.83(42.97-44.69)$ & $44.42(43.13-45.72)$ \\
\hline Shiraz & $40.74 \pm 0.18$ & $0.99 \pm 0.12$ & $0.32 \pm 0.085$ & $42.33(41.96-42.70)$ & $42.64(42.24-43.04)$ & $42.95(42.48-43.41)$ \\
\hline Tabriz & $38.06 \pm 0.23$ & $1.24 \pm 0.16$ & $0.30 \pm 0.10$ & $39.58(39.58-40.56)$ & $40.47(39.92-41.03)$ & $40.88(40.18-41.57)$ \\
\hline Van & $32.06 \pm 0.29$ & $1.60 \pm 1.60$ & $0.22 \pm 0.09$ & $34.90(34.14-35.65)$ & $35.54(34.65-36.43)$ & $36.24(35.09-37.39)$ \\
\hline
\end{tabular}

waves, especially in the desert areas such as in Saudi Arabia.

EVT distributions have been used to model the frequency and cluster maxima of heat waves and trends have been detected. Other characteristics of heat waves e.g. cluster duration and maximum temperatures within clusters have been explored. We found that the highest temperature in the summer season (as defined in this study) is increasing in Dhahran, Doha, Kuwait and Isparta, and for the other stations no significant changes could be detected. On the other hand, we found that the number of heat waves, defined as clusters, increased drastically over the last four decades at most stations, whereas the intensity and the duration of the heat waves did not change. The return levels of the highest maximum temperatures could be quantified using GEV distribution.

The comparison of our results to similar studies using ETCDDI indices shows discrepancies because of the different methodology and definitions of summer and heat waves applied here. For example, Kostopoulo et al. (2005) found a significant positive trend in the Tx90 index (which is defined as 'days with Tmax > 90th percentile of daily Tmax of the base period') across the eastern Mediterranean indicating an increase in the very warm days. This could not be generalized for this region in our analysis. A clear trend in the highest maximum temperatures has been observed only in the Middle East stations. Similarly, Kuglitsch et al. (2010) used modified ETCDDI indices to quantify the trends in heat wave intensity, heat wave length and heat wave number in the eastern Mediterranean, with a high station den- sity in Turkey and for the period 1960-2006. They found a large increase in the mean intensity, length and number over this period. This could not be confirmed in our analysis, in which only the cluster number increased. On the other hand, our results are consistent with the results of Zhang et al. (2005) for the Middle East region, Donat et al. (2014) for the Arab region and Almazroui et al. (2014) for Saudi Arabia, in which significant, increasing trends have been found in the annual maximum of daily maximum temperature.

The focus of this study is to explore new methods and approaches to statistically characterize heat waves in a region very concerned with heat waves. The methodology allows us to understand several aspects of heat waves using robust statistical methods. EVT offers a broad range of tools to analyze heat waves and their characteristics.

This study includes several assumptions related to the definition of a heat wave. The studied station data span several climate zones, and the description of heat waves is based on different methods. Using the EVT methods allows an 'objective' definition, based only on statistical criteria. Nevertheless, the choice of the threshold above which a heat wave is defined can be crucial. The fitting to the GPD of the temperature anomalies is possible only if the chosen threshold is high enough so that the assumption of exceeding a sufficiently high threshold is valid. The choice of the $95 \%$ quantile threshold needs to be examined carefully in case it is high enough to satisfy this assumption. Similarly, the 'summer' season has been defined based on the data in this study, and the 
fact that the probability of the temperature exceeding the threshold is high enough to be considered. This explains the length of the season considered. These choices can influence the results.

The use of EVT helps to quantify the return levels of severe heat waves, with a robust assessment of their characteristics and their trends. Future investigation of 21st century projections of heat waves by climate models would provide an improved understanding and better tools for policy makers, e.g. in view of adaptation in the energy and water sectors in this region.

\section{LITERATURE CITED}

Alexander LV, Zhang X, Peterson TC, Caesar J and others (2006) Global observed changes in daily climate extremes of temperature and precipitation. J Geophys Res Atmos 111:D05109, doi:10.1029/2005JD006290

Almazroui M, Nazrul Islam M, Dambul R, Jones PD (2014) Trends of temperature extremes in Saudi Arabia. Int J Climatol 34:808-826

> Athar H (2014) Trends in observed extreme climate indices in Saudi Arabia during 1979-2008. Int J Climatol 34: 1561-1574.

> Christensen JH, Christensen OB (2007) A summary of the PRUDENCE model projections of changes in European climate by the end of this century. Clim Change 81(Suppl1):7-30

Coelho CAS, Ferro CAT, Stephenson DB, Steinskog DJ (2008) Methods for exploring spatial and temporal variability of extreme events in climate data. J Clim 21: 2072-2092

Coles S (2001) An introduction to statistical modeling of extreme values. Springer, London

> Diffenbaugh NS, Pal JS, Giorgi F, Gao X (2007) Heat stress intensification in the Mediterranean climate change hotspot. Geophys Res Lett 34:L11706, doi:10.1029/2007 GL030000

Donat MG, Peterson TC, Brunet M, King $\mathrm{AD}$ and others (2014) Changes in extreme temperature and precipitation in the Arab region: long-term trends and variability related to ENSO and NAO. Int J Climatol 34:581-592

Efthymiadis D, Goodess CM, Jones PD (2011) Trends in Mediterranean gridded temperature extremes and largescale circulation influences. Nat Hazards Earth Syst Sci 11:2199-2214.

Erlat E, Türkeş M (2012) Analysis of observed variability and trends in numbers of frost days in Turkey for the period 1950-2010. Int J Climatol 32:1889-1898

Erlat E, Türkeş M (2013) Observed changes and trends in numbers of summer and tropical days, and the 2010 hot summer in Turkey. Int J Climatol 33:1898-1908

Evans JP (2009) 21st century climate change in the Middle East. Clim Change 92:417-432

Ferris R, Ellis RH, Wheeler TR, Hadley P (1998) Effect of high temperature stress at anthesis on grain yield and biomass of field grown crops of wheat. Ann Bot 82:631-639

> Fischer EM, Schär C (2010) Consistent geographical patterns of changes in high-impact European heatwaves. Nat Geosci 3:398-403
Folland CK, Miller C, Bader D, Crowe M and others (1999) Workshop on indices and indicators for climate extremes, Asheville, NC, USA, 3-6 June 1999: Breakout Group C: temperature indices for climate extremes. Clim Change 42:31-43

Förster H, Lilliestam J (2010) Modeling thermoelectric power generation in view of climate change. Reg Environ Change 10:327-338

> Fowler HJ, Ekström M, Kilsby CG, Jones PD (2005) New estimates of future changes in extreme rainfall across the UK using regional climate model integrations. 1. Assessment of control climate. J Hydrol (Amst) 300:212-233

Frich P, Alexander LV, Della-Marta P, Gleason B, Haylock M, Klein Tank AMG, Peterson T (2002) Observed coherent changes in climatic extremes during the second half of the twentieth century. Clim Res 19:193-212

> Furrer EM, Katz RW, Walter MD, Furrer R (2010) Statistical modeling of hot spells and heat waves. Clim Res 43: 191-205

> Gao X, Giorgi F (2008) Increased aridity in the Mediterranean region under greenhouse forcing estimated from high-resolution simulations with a regional climate model. Global Planet Change 62:195-209

Hansen J, Sato M, Ruedy R (2012) Perception of climate change. Proc Natl Acad Sci USA 109:E2415-E2423

- Hertig E, Seubert S, Jacobeit J (2010) Temperature extremes in the Mediterranean area: trends in the past and assessments for the future. Nat Hazards Earth Syst Sci 10: 2039-2050.

IPCC (Intergovernmental Panel on Climate Change) (2007) Climate change 2007: impacts, adaptation and vulnerability. Summary for policymakers. Contribution of Working Group II to the Fourth Assessment Report of the Intergovernmental Panel on Climate Change. Cambridge University Press, Cambridge

IPCC (Intergovernmental Panel on Climate Change) (2012) Managing the risks of extreme events and disasters to advance climate change adaptation. A Special Report of Working Groups I and II of the Intergovernmental Panel on Climate Change. Cambridge University Press, Cambridge

> Jones PD, Horton EB, Folland CK, Hulme M, Parker DE, Basnett TA (1999) The use of indices to identify changes in climatic extremes. Clim Change 42:131-149

> Karl TR, Easterling DR (1999) Climate extremes: selected review and future research directions. Clim Change 42 : 309-325

Katz RW (2010) Statistics of extremes in climate change. Clim Change 100:71-76

> Kharin VV, Zwiers FW (2000) Changes in the extremes in an ensemble of transient climate simulations with a coupled atmosphere-ocean GCM. J Clim 13:3760-3788

> Kharin VV, Zwiers FW (2005) Estimating extremes in transient climate change simulations. J Clim 18:1156-1173

> Kharin VV, Zwiers FW, Zhang X (2005) Intercomparison of near-surface temperature and precipitation extremes in AMIP-2 simulations, reanalyses, and observations. J Clim 18:5201-5223

Kharin VV, Zwiers FW, Zhang X, Hegerl GC (2007) Changes in temperature and precipitation extremes in the IPCC ensemble of global coupled model simulations. J Clim 20:1419-1444

Klein Tank AMG, Wijngaard JB, Können GP, Böhm R and others (2002) Daily dataset of 20th-century surface air temperature and precipitation series for the European 
Climate Assessment. Int J Climatol 22:1441-1453

Klein Tank AMG, Zwiers FW, Zhang X (2009) Guidelines on analysis of extremes in a changing climate in support of informed decisions for adaptation. WMO-TD No. 1500, WMO, Geneva

Klok EJ, Klein Tank AMG (2009) Updated and extended European dataset of daily climate observations. Int J Climatol 29:1182-1191

Koch H, Vögele S (2009) Dynamic modelling of water demand, water availability and adaptation strategies for power plants to global change. Ecol Econ 68:2031-2039

Koenker R, Bassett G Jr (1978) Regression quantiles. Econometrica J Econometric Soc 46:33-50

Koppe C, Kovats RS, Jendritzky G, Menne B (2004) Heatwaves: risks and responses. Health and Global Environmental Change Series, Vol. 2, WHO Regional Office for Europe, Geneva

Kostopoulou E, Jones PD (2005) Assessment of climate extremes in the Eastern Mediterranean. Meteorol Atmos Phys 89:69-85

Kostopoulou E, Giannakopoulos C, Hatzaki M, Karali A, Hadjinicolaou P, Lelieveld J, Lange MA (2014) Spatiotemporal patterns of recent and future climate extremes in the eastern Mediterranean and Middle East region. Nat Hazards Earth Syst Sci 14:1565-1577.

Kousari MR, Ahani H, Hendi-zadeh R (2013) Temporal and spatial trend detection of maximum air temperature in Iran during 1960-2005. Global Planet Change 111:97-110

Kuglitsch FG, Toreti A, Xoplaki E, Della-Marta PM, Zerefos CS, Türkeş M, Luterbacher J (2010) Heat wave changes in the eastern Mediterranean since 1960. Geophys Res Lett 37:L04802, doi:10.1029/2009GL041841

Leadbetter MR, Lindgren G, Rootzén H (1983) Extremes and related properties of random sequences and processes. Springer, New York, NY

Lelieveld J, Hadjinicolaou P, Kostopoulou E, Giannakopoulos C, Pozzer A, Tanarhte M, Tyrlis E (2013) Model projected heat extremes and air pollution in the eastern Mediterranean and Middle East in the twenty-first century. Reg Environ Change 14:1937-1949

- Moriondo M, Good P, Durao R, Bindi M, Giannakopoulos C, Corte-Real J (2006) Potential impact of climate change on fire risk in the Mediterranean area. Clim Res 31:85-95

> Naveau P, Nogaj M, Ammann C, Yiou P, Cooley D, Jomelli V (2005) Statistical methods for the analysis of climate extremes. CR Geosci 337:1013-1022

> Önol B, Semazzi FHM (2009) Regionalization of climate change simulations over the eastern Mediterranean. J Clim 22:1944-1961

- Orlowsky B, Seneviratne SI (2011) Global changes in extremes events: regional and seasonal dimension. Clim Change 110:669-696

Peterson TC, Easterling DR, Karl TR, Groisman P and others (1998) Homogeneity adjustments of in situ atmospheric climate data: a review. Int J Climatol 18:1493-1517

Rahimzadeh F, Asgari A, Fattahi E (2009) Variability of extreme temperature and precipitation in Iran during recent decades. Int J Climatol 29:329-343

Stephenson A, Gilleland E (2006) Software for the analysis of extreme events: the current state and future directions. Extremes 8:87-109

> Tayanç M, Im U, Dogruel M, Karaca M (2009) Climate change in Turkey for the last half century. Clim Change 94:483-502

- Tebaldi C, Knutti R (2007) The use of the multi-model ensemble in probabilistic climate projections. Philos Trans R Soc Lond A 365:2053-2075

van den Brink HW, Können GP, Opsteegh JD (2004) Statistics of extreme synoptic-scale wind speeds in ensemble simulations of current and future climate. J Clim 17: 4564-4574

Walter MD (2008) Application of the statistical theory of extreme values to heat waves. www.isse.ucar.edu/ extremevalues/MDWFinalPaper.pdf

> Wang XL (2008) Penalized maximal F-test for detecting undocumented mean-shifts without trend-change. J Atmos Ocean Technol 25:368-384

WMO (2011) World's 10th warmest year, warmest year with La Niña event, lowest Arctic sea ice volume. Press release no. 935, WMO, Geneva

Zhang X, Aguilar E, Sensoy S, Melkonyan H and others (2005) Trends in Middle East climate extreme indices from 1950 to 2003. J Geophys Res 110:D22104, doi:10. 1029/2005JD006181 
Appendix
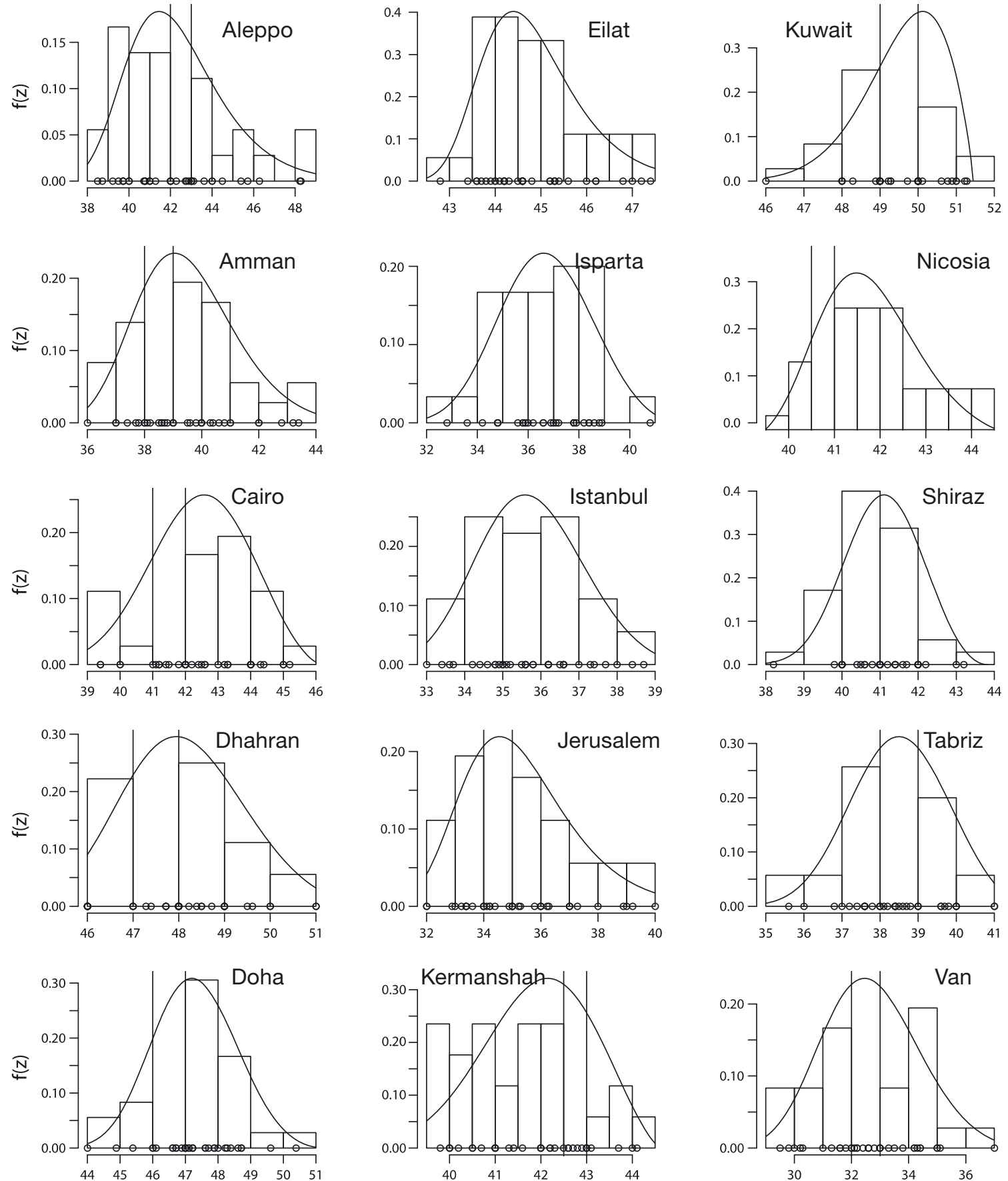

Fig. A1. Histograms and estimated generalized extreme value (GEV) probability functions for the highest summer maximum temperature at the 15 stations 

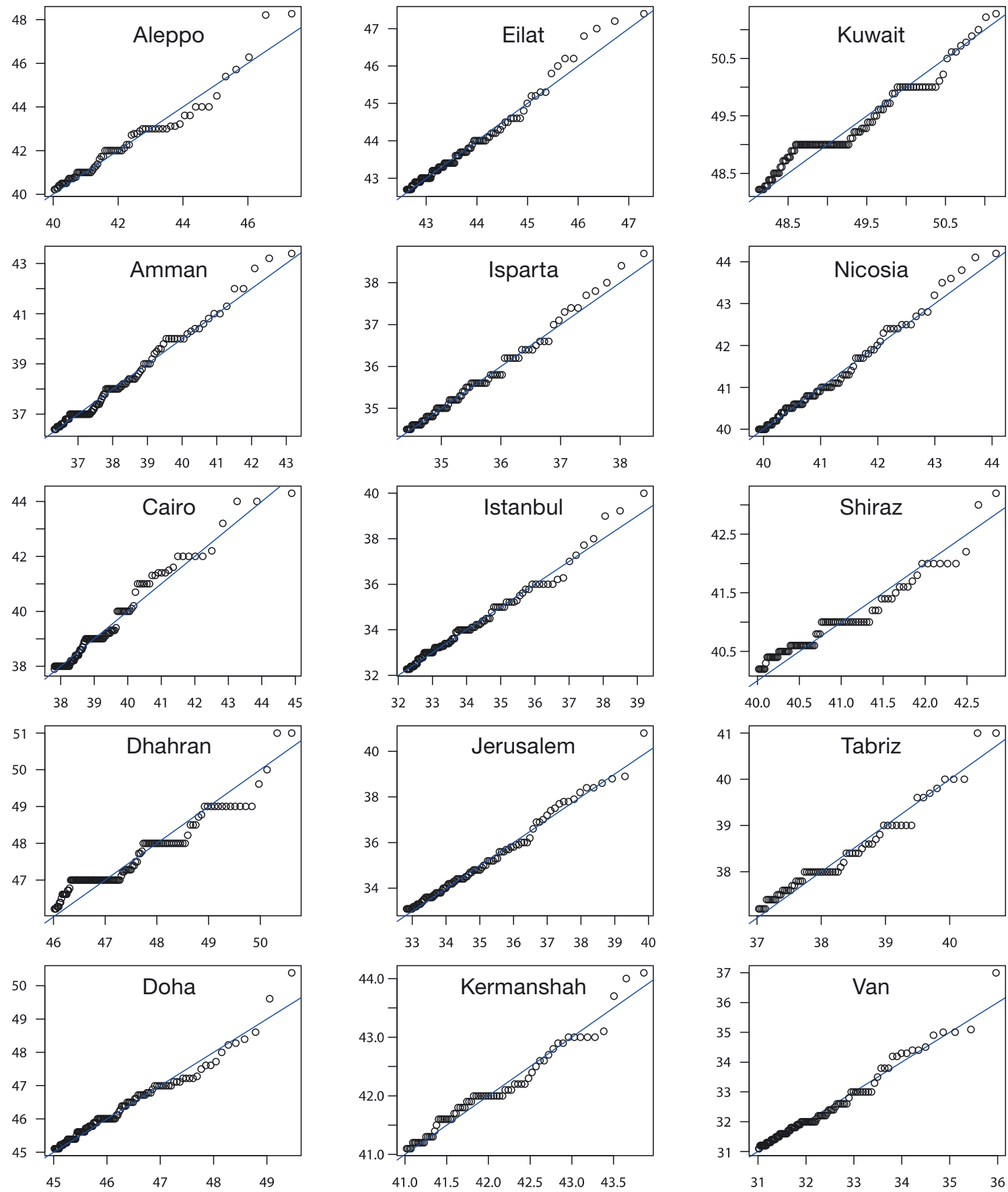

Fig. A2. Q-Q plots for the cluster maximum excess under the generalized Pareto (GP) distribution at the 15 stations

Editorial responsibility: Filippo Giorgi, Trieste, Italy
Submitted: May 13, 2014; Accepted: January 8, 2015

Proofs received from author(s): March 30, 2015, 2015 